\title{
Alogliptin ameliorates postprandial lipemia and postprandial endothelial dysfunction in non- diabetic subjects: a preliminary report
}

Yoko Noda' ${ }^{1}$, Toru Miyoshi ${ }^{1,2^{*}}$, Hiroki Oe ${ }^{3}$, Yuko Ohno ${ }^{1}$, Kazufumi Nakamura', Norihisa Toh ${ }^{1}$, Kunihisa Kohno ${ }^{1}$, Hiroshi Morita ${ }^{1,2}$, Kengo Kusano ${ }^{1}$ and Hiroshi Ito ${ }^{1}$

\begin{abstract}
Background: Postprandial hyperlipidemia impairs endothelial function and participates in the development of atherosclerosis. We investigated the postprandial effects of a dipeptidyl peptidase IV inhibitor, alogliptin, on endothelial dysfunction and the lipid profile.
\end{abstract}

Methods: A randomized cross-over trial design in 10 healthy volunteers ( 8 males and 2 females, $35 \pm 10$ years) was performed. The postprandial effects before and after a 1-week treatment of $25 \mathrm{mg} /$ day alogliptin on endothelial function were assessed with brachial artery flow-mediated dilation (FMD) and changing levels of lipids, apolipoprotein B48 (apoB-48), glucose, glucagon, insulin, and glucagon-like peptide-1 (GLP-1) during fasting and at $2,4,6$, and $8 \mathrm{~h}$ after a standard meal loading test.

Results: Alogliptin treatment significantly suppressed the postprandial elevation in serum triglyceride (incremental area under the curve [AUC]; $279 \pm 31$ vs. $182 \pm 32 \mathrm{mg} \mathrm{h} / \mathrm{dl}, \mathrm{p}=0.01$ ), apoB-48 (incremental AUC; $15.4 \pm 1.7$ vs. $11.7 \pm 1.1 \mu \mathrm{g} \mathrm{h} / \mathrm{ml}, \mathrm{p}=0.04$ ), and remnant lipoprotein cholesterol (RLP-C) (incremental AUC: $29.3 \pm 3.2$ vs. $17.6 \pm$ $3.3 \mathrm{mg} \mathrm{h} / \mathrm{dl}, \mathrm{p}=0.01)$. GLP-1 secretion was significantly increased after alogliptin treatment. Postprandial endothelial dysfunction (maximum decrease in\%FMD, from $-4.2 \pm 0.5 \%$ to $-2.6 \pm 0.4 \%, p=0.03$ ) was significantly associated with the maximum change in apoB-48 $(r=-0.46, p=0.03)$ and RLP-C $(r=-0.45, p=0.04)$.

Conclusion: Alogliptin significantly improved postprandial endothelial dysfunction and postprandial lipemia, suggesting that alogliptin may be a promising anti-atherogenic agent.

Keywords: Dipeptidyl peptidase IV inhibitor, Postprandial lipid, Triglyceride-rich lipoprotein, Endothelial dysfunction, Alogliptin

\section{Introduction}

Large prospective studies have shown that non-fasting postprandial triglyceride (TG) concentrations predict cardiovascular risk better than fasting TG concentrations and that this relationship is independent of traditional coronary risk factors [1,2]. TG-rich lipoproteins, which consist of chylomicrons assembled by TG, dietary cholesterol, and apolipoprotein B-48 (apoB-48), are highly atherogenic and

\footnotetext{
* Correspondence: miyoshit@cc.okayama-u.ac.jp

'Department of Cardiovascular Medicine, Okayama University Graduate

School of Medicine, Dentistry and Pharmaceutical Sciences, Okayama, Japan

2Department of Cardiovascular Therapeutics, Okayama University Graduate

School of Medicine, Dentistry and Pharmaceutical Sciences, 2-5-1,

Shikata-choOkayama 700-8558, Japan

Full list of author information is available at the end of the article
}

contribute to the development of coronary heart disease. Thus, the increased risk of cardiovascular events associated with non-fasting TG concentrations may reflect atherogenic properties of TG-rich lipoproteins generated during the postprandial period [3]. Studies have shown that postprandial lipemia contributes to the production of proinflammatory cytokines and oxidative stress, resulting in endothelial dysfunction even in healthy normolipidemic people $[4,5]$. Furthermore, other studies demonstrated that postprandial hyperlipemia caused by oral fat intake impairs endothelial dysfunction as detected with flowmediated dilatation (FMD) of the brachial artery in healthy volunteers. This endothelial dysfunction is associated with postprandial TG-rich lipoproteins [6,7]. 
Therefore, identification of novel therapeutic approaches that would beneficially affect postprandial concentrations of lipids is of great interest.

Alogliptin is a potent and selective inhibitor of dipeptidyl peptidase IV (DPP-4) and has been shown to reduce fasting and postprandial glucose levels in patients with type 2 diabetes, presumably by inhibiting the inactivation of glucagon-like peptide-1 (GLP-1) and glucose-dependent insulinotropic polypeptide (GIP), thereby improving islet function [8-10]. Recent clinical studies have reported that DPP-4 inhibitors such as vildagliptin and sitagliptin improve postprandial atherogenic TG-rich lipoprotein levels in patients with type 2 diabetes $[11,12]$. However, the effects of other DPP-4 inhibitors on postprandial lipemia-induced endothelial dysfunction have not been fully evaluated.

The aim of this study was to investigate the effects of alogliptin on postprandial triglyceride (TG)-rich lipoprotein and postprandial lipemia-induced endothelial dysfunction.

\section{Methods \\ Participants}

Ten volunteers, including eight men and two women, were recruited. The study consisted of two 1-week cross-over treatment periods with $25 \mathrm{mg} /$ day alogliptin and placebo in random order, including a 1-week washout period between the two phases. All participants underwent medical checkups. None of the 10 volunteers had hypertension, impaired glucose tolerance, dyslipidemia, or cerebrovascular or cardiovascular disease, but three volunteers were current smokers. Family histories were obtained from medical interviews. Impaired glucose tolerance was defined as 2-h glucose level of $140-199 \mathrm{mg} / \mathrm{dl}$ after the meal loading test [13], and dyslipidemia was defined as one or more of the following criteria at the fasting state: (1) serum triglyceride $\geq 150 \mathrm{mg} / \mathrm{dL}$, (2) HDL-cholesterol $<40 \mathrm{mg} / \mathrm{dL}$, and (3) LDL-cholesterol $\geq 140 \mathrm{mg} / \mathrm{dL}$ [14]. Lipid profiles and endothelial function, which was assessed with brachial artery FMD during fasting and at 2, 4, 6, and $8 \mathrm{~h}$ after an oral cookie loading test, were determined following each phase of treatment. Participants were instructed to take one tablet after their morning meal. This study was approved by the Ethics Committee of Okayama University Graduate School of Medicine, Dentistry, and Pharmaceutical Sciences, and written informed consent was obtained from all volunteers before beginning the protocol.

\section{Study protocol}

After overnight fasting for at least $8 \mathrm{~h}$, a cookie test was performed. The cookie consisted of $75 \mathrm{~g}$ carbohydrate (flour starch and maltose), $28.5 \mathrm{~g}$ fat (butter), and $8 \mathrm{~g}$ protein for a total of $592 \mathrm{kcal}$ per a carton (SARAYA Corp., Osaka, Japan) [15]. Participants were instructed to ingest the cookie with water within $20 \mathrm{~min}$. Time measurement was started when half the cookie had been ingested.
Venous blood samples were drawn, and endotheliumdependent vascular function, as assessed with FMD of the brachial artery, was determined during the fasting state before cookie ingestion and at 2, 4, 6, and $8 \mathrm{~h}$ after the cookie load. Endothelium-independent dilation, as assessed with nitroglycerin-mediated dilation (NMD), was also measured during fasting before cookie ingestion and $8 \mathrm{~h}$ after the cookie load. For the $8 \mathrm{~h}$ after eating the cookie, the participants were instructed not to eat anything else. Measurements of FMD and NMD were performed by the same technician, who was blinded to the study design and medication status.

\section{Measurement of biochemical parameters}

The following parameters during fasting before cookie ingestion were measured: serum total cholesterol (Total-C), TG, low-density lipoprotein cholesterol (LDL-C), highdensity lipoprotein cholesterol (HDL-C), remnant lipoprotein cholesterol (RLP-C), apoB-48, adiponectin, soluble vascular cell adhesion molecule 1 (VCAM-1), and plasma glucose levels. HbA1c levels were measured using highperformance liquid chromatography. Concentrations of fasting plasma insulin were measured using a chemiluminescent enzyme immunoassay. Lipid profiles and other markers were measured at SRL Co., Ltd., Tokyo, Japan. Homeostasis model assessment of insulin resistance (HOMA-IR) was calculated as [fasting plasma glucose $(\mathrm{mg} / \mathrm{dl}) \times$ fasting plasma insulin $(\mu \mathrm{IU} / \mathrm{ml}) / 405]$. Serum Total-C, TG, LDL-C, HDL-C, RLP-C, apoB-48, plasma glucose, and soluble VCAM-1 were measured at 2, 4, 6, and $8 \mathrm{~h}$ after the cookie load. To compare the postprandial changes in these parameters before and after treatment for 4 weeks, the area under the curve (AUC) was calculated using the trapezoidal method.

\section{FMD measurement}

Endothelium-dependent and -independent dilation was assessed as a parameter of vasodilation according to the guidelines for ultrasound assessment of FMD of the brachial artery [16]. Using a 10-MHz linear-array transducer probe (Unex Company Ltd., Nagoya, Japan), longitudinal images of the brachial artery at baseline were recorded with a stereotactic arm, and measurements of artery diameter were made after supine rest for $\geq 5 \mathrm{~min}$. The diameter of the artery was measured from clear anterior (media-adventitia) and posterior (intima-media) interfaces, which were manually determined. Then, suprasystolic compression (50 $\mathrm{mmHg}$ higher than systolic blood pressure) was performed at the right forearm for $5 \mathrm{~min}$, and measurements of artery diameter were made continuously from $30 \mathrm{~s}$ before to $\geq 2 \mathrm{~min}$ after cuff release. After $\geq 10 \mathrm{~min}$ of rest from FMD measurement, artery diameter at baseline and for $5 \mathrm{~min}$ after administration of $0.3 \mathrm{mg}$ sublingual nitroglycerin was also measured. Maximum vasodilation 
was then evaluated from the change in artery diameter after release of occlusion (\%FMD) and after administration of nitroglycerin (\%NMD).

\section{Statistical analysis}

Sample size was determined based on the estimated FMD reported in another recent study [7]. We assumed that the mean improvement in postprandial\%FMD was $2.7 \%$ and the standard deviation (SD) was $2.0 \%$. To use a two-sided test for differences, a minimal sample size of 10 participants was required in each group to detect statistical differences in\%FMD with a power of $80 \%$ and an $\alpha$-type error of $5 \%$ in statistical analysis. Results and data in the figures are expressed as the mean \pm standard error (SE). Categorical variables were compared using the $\chi^{2}$ test or Fisher's exact test. Differences in lipid profile and endothelial function between the two groups were compared using the Wilcoxon signed-ranks test. Pearson correlation coefficients were used to assess the relationships between maximum reduction in postprandial\%FMD and lipid profiles. Values of $\mathrm{p}<0.05$ were considered significant.

\section{Results}

\section{Characteristics of participants}

The mean age and body mass index of these volunteers were $35 \pm 10$ years and $23.9 \pm 4.1 \mathrm{~kg} / \mathrm{m}^{2}$, respectively. Participants maintained their weight throughout the study. Table 1 shows the lipid/lipoprotein profile and the glycemic parameters of the participants following each 1-week phase of either control or treatment with $25 \mathrm{mg} /$ day alogliptin. During fasting, 1-week treatment with alogliptin did not affect the lipid/lipoprotein profile or the levels of adiponectin and soluble VCAM-1. Alogliptin significantly increased GLP-1 levels with no significant impact on fasting blood glucose or HOMA-IR (insulin resistance). No significant differences were observed in systolic and diastolic blood pressure following alogliptin treatment.

\section{Postprandial lipid and glucose homeostasis}

The levels of lipid/lipoprotein, parameters of glucose homeostasis, and soluble VCAM-1 in the postprandial state are shown in Figure 1 and Additional file 1: Table S1. The serial changes in parameters following each 1-week phase of either control or treatment with alogliptin are shown in Figure 1. In the control group, the postprandial levels of serum TG, RLP-C, apoB-48, and GLP-1 increased and peaked at 2 or $4 \mathrm{~h}$ and then returned to baseline at $8 \mathrm{~h}$. The levels of glucose, total-C, LDL-C, HDL-C, and soluble VCAM-1 did not change significantly during the postprandial state. Therefore, the nominal maximum changes and the incremental AUCs of TG, RLP-C, ApoB-48, glucose, and GLP-1 were calculated. The total AUCs of total-C, LDL-C, HDL-C, glucagon, and soluble VCAM-1 were also calculated for comparison.
Table 1 Characteristics of participants

\begin{tabular}{|c|c|c|c|}
\hline & $\begin{array}{l}\text { Control } \\
(n=10)\end{array}$ & $\begin{array}{c}\text { Alogliptin } \\
(n=10)\end{array}$ & p value \\
\hline Age (years) & $35 \pm 10$ & - & - \\
\hline Male (\%) & $8(80)$ & - & - \\
\hline Current Smoker (\%) & $3(30)$ & - & - \\
\hline $\mathrm{HbA} 1 \mathrm{c}(\%)$ & $4.6 \pm 0.3$ & - & - \\
\hline BMI $\left(\mathrm{kg} / \mathrm{m}^{2}\right)$ & $23.9 \pm 4.1$ & $23.9 \pm 3.4$ & 0.86 \\
\hline Systolic blood pressure (mmHg) & $122 \pm 3$ & $121 \pm 3$ & 0.35 \\
\hline Diastolic blood pressure (mmHg) & $71 \pm 2$ & $71 \pm 2$ & 0.99 \\
\hline Heart rate (beats/min) & $62 \pm 3$ & $61 \pm 2$ & 0.20 \\
\hline Total-C (mg/dl) & $185.3 \pm 10.6$ & $180.7 \pm 9.9$ & 0.58 \\
\hline $\mathrm{LDL}-\mathrm{C}(\mathrm{mg} / \mathrm{dl})$ & $103.2 \pm 8.9$ & $102.2 \pm 9.3$ & 0.72 \\
\hline $\mathrm{HDL}-\mathrm{C}(\mathrm{mg} / \mathrm{dl})$ & $66.3 \pm 3.1$ & $64.2 \pm 3.4$ & 0.29 \\
\hline TG (mg/dl) & $73.7 \pm 10.2$ & $63.4 \pm 7.9$ & 0.08 \\
\hline $\mathrm{RLP}-\mathrm{C}(\mathrm{mg} / \mathrm{dl})$ & $8.4 \pm 1.2$ & $6.7 \pm 0.8$ & 0.28 \\
\hline ApoB-48 ( $\mu \mathrm{g} / \mathrm{ml})$ & $2.5 \pm 0.3$ & $2.2 \pm 0.2$ & 0.19 \\
\hline Glucose (mg/dl) & $93.0 \pm 2.0$ & $94.3 \pm 2.1$ & 0.54 \\
\hline Glucagon (pg/ml) & $63.5 \pm 5.4$ & $59.4 \pm 2.8$ & 0.44 \\
\hline Insulin $(\mu \mathrm{lU} / \mathrm{ml})$ & $4.8 \pm 0.8$ & $4.9 \pm 1.3$ & 0.38 \\
\hline HOMA-IR & $1.1 \pm 0.2$ & $1.1 \pm 0.3$ & 0.51 \\
\hline GLP-1 (pmol/l) & $3.2 \pm 0.2$ & $5.2 \pm 0.7$ & 0.03 \\
\hline Adiponectin $(\mu \mathrm{g} / \mathrm{ml})$ & $9.6 \pm 0.8$ & $9.7 \pm 0.7$ & 0.31 \\
\hline Soluble VCAM-1 (ng/ml) & $629 \pm 72$ & $606 \pm 50$ & 0.76 \\
\hline
\end{tabular}

Data are the mean $\pm \mathrm{SE}$ or frequency counts (percentages), as appropriate. $\mathrm{BMI}$, body mass index; LDL-C, low-density lipoprotein cholesterol; HDL-C, high-density lipoprotein cholesterol; TG, triglyceride; RLP-C, remnant lipoprotein cholesterol; ApoB-48, apolipoprotein B-48; HOMA-IR, homeostasis model assessment of insulin resistance; GLP-1, glucagon-like peptide-1; VCAM-1, vascular cell adhesion molecule-1.

The maximum changes in postprandial TG, RLP-C, ApoB-48, and GLP-1 were significantly smaller in the alogliptin group compared with the control group (Table 2). The incremental AUCs of serum TG, RLP-C, and apoB-48 were significantly lower in the alogliptin group than in the control group (incremental AUC of TG: $279 \pm 31 \mathrm{mg}$ vs. $182 \pm 32 \mathrm{mg} \mathrm{h} / \mathrm{dl}, \mathrm{p}=0.01$; RLP-C: $29.3 \pm 3.2$ vs. $17.6 \pm$ $3.3 \mathrm{mg} \mathrm{h} / \mathrm{dl}, \mathrm{p}=0.01$; apoB- $48: 15.4 \pm 1.7$ vs. $11.7 \pm$ $1.1 \mu \mathrm{g} \mathrm{h} / \mathrm{ml}, \mathrm{p}=0.04)$. No differences in the total AUCs of total-C, LDL-C, or HDL-C were observed between the alogliptin group and the control groups (total AUC of total-C: $1452 \pm 252$ vs. $1489 \pm 248 \mathrm{mg} \mathrm{h} / \mathrm{dl}, \mathrm{p}=0.68$, LDL-C: $814 \pm$ 228 vs. $819 \pm 218 \mathrm{mg} \mathrm{h} / \mathrm{dl}, \mathrm{p}=0.72$, HDL-C: $514 \pm 71$ vs. $532 \pm 79 \mathrm{mg} \mathrm{h} / \mathrm{dl}, \mathrm{p}=0.10$ ).

Regarding parameters of glucose homeostasis, there were no significant differences in the incremental AUCs of glucose or insulin between the alogliptin and control groups (incremental AUC of glucose: $78 \pm 15$ vs. $77 \pm$ $8 \mathrm{mg} \mathrm{h} / \mathrm{dl}, \mathrm{p}=0.58$, insulin: $48.3 \pm 10.9$ vs. $49.4 \pm 14.7$, $\mathrm{p}=0.96$ ), although the incremental AUC of GLP-1 was increased in the alogliptin group (33.8 \pm 5.2 vs. $18.2 \pm$ 

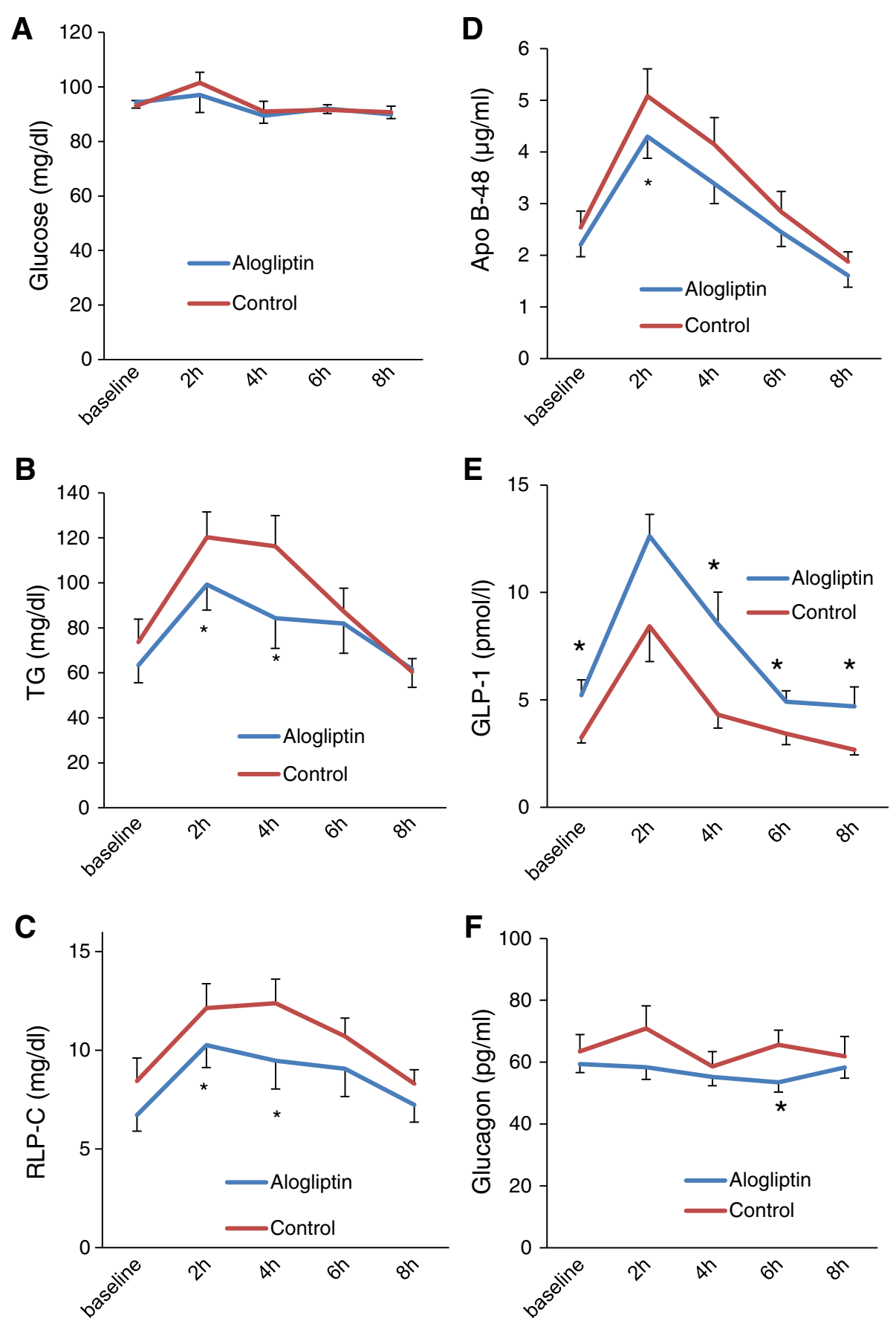

Figure 1 The serial change in glucose (A), triglyceride (TG) (B), remnant lipoprotein cholesterol (RLP-C) (C), apolipoprotein B-48 (ApoB-48) (D), glucagon-like peptide-1 (GLP-1) (E), and glucagon (F). ${ }^{*} \mathrm{p}<0.05 \mathrm{Vs}$. control group.

4.4 $\mathrm{pmol} \mathrm{h/l,} \mathrm{p}=0.02)$. The total AUC of glucagon was decreased significantly after alogliptin treatment $(451.9 \pm$ 21.9 vs. $515.6 \pm 30.4 \mathrm{pg} \mathrm{h} / \mathrm{ml}, \mathrm{p}=0.02)$. No significant difference was observed in the level of soluble VCAM-1 between the alogliptin and control groups $(4931 \pm 1528$ vs. $4935 \pm 1411 \mathrm{ng} \mathrm{h} / \mathrm{ml}, \mathrm{p}=0.79$ ).

\section{Postprandial endothelial function}

Comparison of postprandial endothelial function, which was assessed as\%FMD, between the control and alogliptin groups is shown in Figure 2. In the control group, postprandial\%FMD decreased significantly, reached the lowest level at $4 \mathrm{~h}$ (from $11.8 \pm 0.6$ to $7.7 \pm 0.3 \%$, fasting 
Table 2 Maximum change in lipids and glucose metabolism in the alogliptin and control groups

\begin{tabular}{lccc}
\hline & Control & Alogliptin & p \\
\hline TG $(\mathrm{mg} / \mathrm{dl})$ & $59.7 \pm 7.8$ & $48.3 \pm 6.4$ & 0.01 \\
RLP-C $(\mathrm{mg} / \mathrm{dl})$ & $6.1 \pm 0.6$ & $4.8 \pm 0.7$ & 0.02 \\
ApoB-48 $(\mu \mathrm{g} / \mathrm{ml})$ & $4.0 \pm 0.4$ & $2.8 \pm 0.2$ & 0.01 \\
Glucose $(\mathrm{mg} / \mathrm{dl})$ & $20.5 \pm 2.4$ & $20.4 \pm 3.9$ & 0.51 \\
Insulin $(\mu \mathrm{lU} / \mathrm{ml})$ & $19.4 \pm 6.3$ & $18.2 \pm 4.8$ & 0.87 \\
GLP-1 $(\mathrm{pmol} / \mathrm{l})$ & $5.4 \pm 1.3$ & $10.2 \pm 1.3$ & 0.04 \\
\hline
\end{tabular}

Data are the mean \pm SE. TG, triglyceride; RLP-C, remnant lipoprotein cholesterol; ApoB-48, apolipoprotein B-48; GLP-1, glucagon-like peptide-1.

vs. $4 \mathrm{~h}, \mathrm{p}<0.01$ ), and recovered at $8 \mathrm{~h}$ (from $11.8 \pm 0.6$ to $12.3 \pm 0.5 \%$, fasting vs. $8 \mathrm{~h}, \mathrm{p}=0.15$ ). The maximum decrease in postprandial\%FMD was significantly improved after alogliptin treatment compared to the control group $(-2.6 \%$ vs. $-4.2 \%, \mathrm{p}=0.03)$. In the analysis of all data using the control and alogliptin groups, linear regression analysis revealed that the maximum reduction in postprandial\%FMD was significantly associated with maximum increases in postprandial TG, RLP-C, and apoB-48 concentrations (TG: $\mathrm{r}=-0.45, \mathrm{p}=0.04$; RLP-C: $\mathrm{r}=-0.45, \mathrm{p}=0.04$; apoB-48: $\mathrm{r}=-0.47, \mathrm{p}=0.03$ ), and tended to be correlated with the maximum change in GLP-1 $(r=0.39, p=0.08)$. However, the maximum reduction in postprandial\%FMD was not associated with the maximum change in postprandial LDL-C, HDL-C, glucose, or soluble VCAM-1.

\section{Discussion}

This study demonstrated that alogliptin treatment significantly reduced postprandial levels of intestinally derived apo-B48-containing lipoproteins, which were induced by a conventional oral cookie loading test (28.5 g fat per person), and that alogliptin improved postprandial lipemiainduced endothelial dysfunction. Considering the significant association between the beneficial change in endothelial dysfunction and the decrease in TG-rich lipoproteins, cardiovascular risk, especially associated with postprandial lipemia, may be reduced with long-term treatment with alogliptin.

Our study with the oral cookie test showed that a greater increase in TG-rich lipoprotein, but not glucose, was correlated with postprandial FMD impairment in healthy volunteers. This study did not include people with impaired glucose tolerance and dyslipidemia. Our finding suggests that the impairment in endothelial dysfunction induced by postprandial lipemia is more common than that induced by postprandial hyperglycemia in the general population. As reported in other studies, postprandial hyperglycemia induces endothelial dysfunction, especially in patients with diabetes mellitus or glucose intolerance. In these patients, an increase in glucose is also associated with postprandial endothelial dysfunction [17]. Furthermore, patients with diabetes mellitus often show dyslipidemia including postprandial hyperlipemia. Therefore, our results suggest that alogliptin therapy possibly improves glucose metabolism as well as postprandial hyperlipemia and postprandial endothelial dysfunction in patients with diabetes mellitus.

Previous studies showed that DPP-4 inhibitors such as vildagliptin and sitagliptin decrease postprandial TG, RLP-C, and apoB-48 levels after a fat-loading test in patients with type 2 diabetes [11,12]; however, our study is the first to show that alogliptin reduces the postprandial increase in triglyceride-rich lipoproteins in nonobese nondiabetic subjects.

This study was not designed to examine the molecular mechanisms underlying the effect of alogliptin on postprandial hyperlipemia, but several mechanisms are possible. A
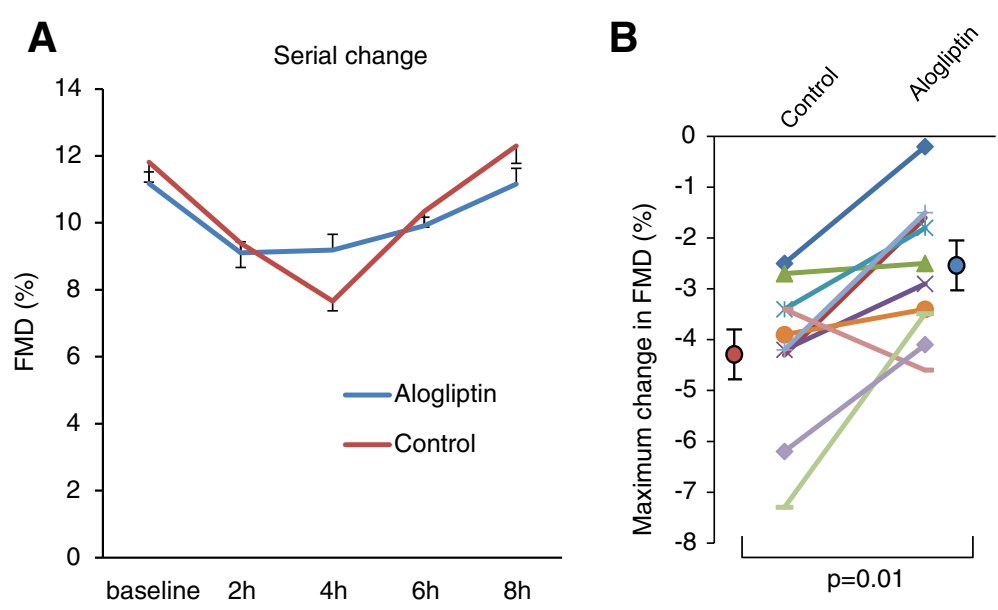

Figure 2 The serial change in endothelial function after cookie ingestion in the alogliptin and control groups. FMD, flow-mediated dilation (A), and maximum decrease in the alogliptin and control groups (B). 
study showed that GLP-1 influences intestinal TG absorption [18], potentially by inhibiting gastric lipase [19]. Animal studies have shown that DPP-4 inhibition or GLP-1 receptor agonists significantly reduce intestinal secretion of TG, cholesterol, and apoB-48, suggesting that GLP-1 may directly regulate lipoprotein assembly or the secretion in enterocytes [20]. As shown in our previous study, administration of ezetimibe, an inhibitor of cholesterol absorption, improves postprandial lipemia-induced endothelial dysfunction, mainly due to suppression of postprandial TG-rich lipoproteins [7]. In our current study, the maximum decrease in FMD was significantly associated with the maximum change in TG, RLP-C, and apoB-48, but not glucose. Although further studies are needed to determine the extent to which decreased TG absorption and increased chylomicron clearance contribute to the alogliptin-induced reduction in postprandial lipid response, these findings support our concept that alogliptin markedly decreases the levels of postprandial TG-rich lipoproteins, resulting in prevention of postprandial lipemia-induced endothelial dysfunction.

Regarding another proposed mechanism of improvement in postprandial endothelial dysfunction, an increase in active GLP-1 after alogliptin administration may have direct favorable effects on vascular function. An experimental study reported that sitagliptin improves endothelial function and reduces proinflammatory cytokines and atherosclerosis in apoE-deficient mice [21]. Another experimental study showed that a GLP-1 analog reduces oxidative stress in endothelial cells [22]. A clinical study showed that vildagliptin improves endothelium-dependent vasodilatation as determined by plethysmography in patients with type 2 diabetes in a fasting state [23]. Postprandial inflammation and oxidative stress, which are well known to affect the metabolism of nitric oxide and the release of vasoconstrictive mediators, result in endothelial dysfunction [5,24]. In our study, we did not examine the effect of alogliptin on postprandial oxidative stress. We evaluated the levels of soluble VCAM-1 as a marker of vascular inflammation, but no significant difference was observed. Therefore, we cannot conclude whether the administration of alogliptin improves postprandial inflammation and oxidative stress. A previous study compared the effects of $\alpha$-glucosidase inhibitors on postprandial glucose/lipid metabolism and endothelial dysfunction in patients with diabetes and showed that miglitol was better than voglibose regarding a greater reduction in triglyceride and a greater induction of GLP-1 [25]. In addition, another study showed that a single dose of exenatide improves postprandial endothelial dysfunction in individuals with impaired glucose tolerance and recent-onset type 2 diabetes. These clinical studies indicate that GLP-1 has direct favorable effects on postprandial endothelial dysfunction [26]. In our current study, no difference was observed between the alogliptin and control groups in glucose levels at $2 \mathrm{~h}$, which was probably due to our use of healthy volunteers. Even though we did not compare alogliptin and other glycemic control agents in this study, a greater spike in GLP-1 after the fat-loading test and/or a greater secretion of GLP-1 after each meal for 1 week in the alogliptin group may have partly contributed to the protective effect on postprandial endothelial dysfunction.

A clinical report showed that sitagliptin treatment for 3 months increases adiponectin levels in patients with diabetes mellitus [27]. This report also suggests that improvement of endothelial function by sitagliptin therapy is associated with the change in adiponectin. An experimental study also showed that sitagliptin significantly increases circulating levels of adiponectin in OLETF rats [28]. Adiponectin has vasoprotective effects via regulation of endothelial nitric oxide synthase in vascular endothelial cells. Even though our study failed to show a significant increase in adiponectin levels after 1 week of treatment with alogliptin-probably owing to short-term administration-the long-term effect of alogliptin therapy on adiponectin levels needs to be elucidated.

There is mixed evidence for the benefits of improved glycemic control on cardiovascular events and mortality in patients with diabetes mellitus. The 10 years of primary follow-up from the landmark UK Prospective Diabetes Study (UKPDS) [29] and three recent outcome studies (the Action to Control Cardiovascular Risk in Diabetes [ACCORD] [30], Action in Diabetes and Vascular Disease: Preterax and Diamicron Modified Release Controlled Evaluation [ADVANCE] [31], and Veterans Affairs Diabetes Trial [VADT] [32]) all failed to demonstrate that intensive glycemic control reduces cardiovascular events and mortality. In contrast, recent studies showed that a DPP-4 inhibitor may reduce cardiovascular events in patients with diabetes [33]. Experimental studies also showed the favorable action of DPP-4 on vascular cells via a GLP-1-independent mechanism [34]. These data indicate that DPP-4 may have potential for preventing cardiovascular events beyond glycemic control; however, another group reported that vildagliptin has no protective effects on cardiac function in a rat model of postmyocardial infarction heart failure [35]. Thus, the cardiovascular benefits of DPP-4 inhibitors beyond glycemic control should be clarified in a future study.

\section{Study limitations}

There are several important limitations of our study. First, this was an open-label study, and the number of participants enrolled in our study was small. Therefore, a degree of selection bias may have occurred. Second, no widely used method for assessing postprandial hyperlipemia has been established, and so various fat-loading tests, such as oral fat meal, fat cream intake, and intravenous fat load, 
have been used in previous studies. We used the cookie test, which provided sufficient information about glucose intolerance and postprandial hyperlipemia [13]. Although the cookie provided a fixed amount of fat $(28.5 \mathrm{~g})$ per person, the amount of fat given per body surface area was not the same in this study. Therefore, the contribution of each person's fat metabolism cannot be ruled out as an influential factor. A meal loading test using $30 \mathrm{~g}$ fat $/ \mathrm{m}^{2}$ body surface area showed a greater increase in TG and RLP compared with that using a fixed amount of fat $(28.5 \mathrm{~g})$ per person, even in healthy volunteers [7]. The effect of alogliptin on postprandial lipemia after the meal loading test with $30 \mathrm{~g} \mathrm{fat} / \mathrm{m}^{2}$ body surface area would also be informative, especially in patients with diabetes or dyslipidemia.

In conclusion, we demonstrated that inhibition of DPP-4 with alogliptin was effective for reducing postprandial elevation of TG-rich lipoproteins and the accompanying induction of postprandial endothelial dysfunction. Alogliptin may be a useful drug for reducing future cardiovascular disease by ameliorating endothelial dysfunction in the postprandial state, even in low-risk patients.

\section{Additional file}

Additional file 1: Table S1. Postprandial changes in lipid profile, glucose metabolism, and endothelial function in the alogliptin and control groups over time.

\section{Abbreviations \\ apoB-48: Apolipoprotein B48; AUC: Area under the curve; BMI: Body mass index; DPP-4: Dipeptidyl peptidase IV; FMD: Flow-mediated dilation; GIP: Glucose-dependent insulinotropic polypeptide; GLP-1: Glucagon-like peptide-1; HDL-C: High-density lipoprotein cholesterol; HOMA- IR: Homeostasis model assessment of insulin resistance; LDL-C: Low-density lipoprotein cholesterol; NMD: Nitroglycerin-mediated dilation; RLP- C: Remnant lipoprotein cholesterol; SD: Standard deviation; SE: Standard error; TG: Triglyceride; Total-C: Total cholesterol; VCAM-1: Vascular cell adhesion molecule 1.}

\section{Competing interest}

The authors declare that they have no competing interest.

\begin{abstract}
Authors' contributions
YN, TM, JO, KN, conceived the study, and participated in its design and coordination and helped to draft the manuscript. YN, TM, YO carried out examinations. NT, KK, HM, KK, HI were involved in drafting the manuscript or revising it critically. All authors read and approved the final manuscript.
\end{abstract}

\section{Acknowledgement}

We thank Koaru Akazawa, Masayo Ohmori, and Miyuki Fujiwara for their excellent technical support.

\footnotetext{
Author details

${ }^{1}$ Department of Cardiovascular Medicine, Okayama University Graduate School of Medicine, Dentistry and Pharmaceutical Sciences, Okayama, Japan. ${ }^{2}$ Department of Cardiovascular Therapeutics, Okayama University Graduate School of Medicine, Dentistry and Pharmaceutical Sciences, 2-5-1, Shikata-choOkayama 700-8558, Japan. ${ }^{3}$ Center of Ultrasonic Diagnostics, Okayama University Hospital, Okayama, Japan.
}

Received: 4 October 2012 Accepted: 14 December 2012 Published: 9 January 2013

\section{References}

1. Bansal S, Buring JE, Rifai N, Mora S, Sacks FM, Ridker PM: Fasting compared with nonfasting triglycerides and risk of cardiovascular events in women. JAMA 2007, 298(3):309-316.

2. Nordestgaard BG, Benn M, Schnohr P, Tybjaerg-Hansen A: Nonfasting triglycerides and risk of myocardial infarction, ischemic heart disease, and death in men and women. JAMA 2007, 298(3):299-308.

3. Zilversmit DB: Atherogenesis: a postprandial phenomenon. Circulation 1979, 60(3):473-485.

4. Bae JH, Bassenge E, Kim KB, Kim YN, Kim KS, Lee HJ, Moon KC, Lee MS, Park KY, Schwemmer M: Postprandial hypertriglyceridemia impairs endothelial function by enhanced oxidant stress. Atherosclerosis 2001, 155(2):517-523.

5. van Oostrom AJ, Sijmonsma TP, Verseyden C, Jansen EH, de Koning EJ, Rabelink TJ, Castro Cabezas M: Postprandial recruitment of neutrophils may contribute to endothelial dysfunction. J Lipid Res 2003, 44(3):576-583.

6. Marchesi S, Lupattelli G, Schillaci G, Pirro M, Siepi D, Roscini AR, Pasqualini L, Mannarino E: Impaired flow-mediated vasoactivity during post-prandial phase in young healthy men. Atherosclerosis 2000, 153(2):397-402.

7. Yunoki K, Nakamura K, Miyoshi T, Enko K, Kohno K, Morita H, Kusano KF, Ito $\mathrm{H}$ : Ezetimibe improves postprandial hyperlipemia and its induced endothelial dysfunction. Atherosclerosis 2011, 217(2):486-491.

8. DeFronzo RA, Fleck PR, Wilson CA, Mekki Q: Efficacy and safety of the dipeptidyl peptidase-4 inhibitor alogliptin in patients with type 2 diabetes and inadequate glycemic control: a randomized, double-blind, placebo-controlled study. Diabetes Care 2008, 31(12):2315-2317.

9. Feng J, Zhang Z, Wallace MB, Stafford JA, Kaldor SW, Kassel DB, Navre M, Shi L, Skene RJ, Asakawa T, Takeuchi K, Xu R, Webb DR, Gwaltney SL 2nd: Discovery of alogliptin: a potent, selective, bioavailable, and efficacious inhibitor of dipeptidyl peptidase IV. J Med Chem 2007, 50(10):2297-2300.

10. Moritoh Y, Takeuchi K, Asakawa T, Kataoka O, Odaka H: Chronic administration of alogliptin, a novel, potent, and highly selective dipeptidyl peptidase- 4 inhibitor, improves glycemic control and beta-cell function in obese diabetic ob/ob mice. Eur J Pharmacol 2008, 588(2-3):325-332.

11. Matikainen N, Manttari S, Schweizer A, Ulvestad A, Mills D, Dunning BE, Foley JE, Taskinen MR: Vildagliptin therapy reduces postprandial intestinal triglyceride-rich lipoprotein particles in patients with type 2 diabetes. Diabetologia 2006, 49(9):2049-2057.

12. Tremblay AJ, Lamarche B, Deacon CF, Weisnagel SJ, Couture P: Effect of sitagliptin therapy on postprandial lipoprotein levels in patients with type 2 diabetes. Diabetes Obes Metab 2011, 13(4):366-373.

13. American Diabetes Association: Diagnosis and classification of diabetes mellitus. Diabetes Care 2005, 28(Suppl 1):S37-S42.

14. Teramoto T, Sasaki J, Ueshima H, Egusa G, Kinoshita M, Shimamoto K, Daida H, Biro S, Hirobe K, Funahashi T, Yokote K, Yokode M: Executive summary of Japan Atherosclerosis Society (JAS) guideline for diagnosis and prevention of atherosclerotic cardiovascular diseases for Japanese. J Atheroscler Thromb 2007, 14(2):45-50.

15. Harano Y, Miyawaki T, Nabiki J, Shibachi M, Adachi T, Ikeda M, Ueda F, Nakano T: Development of cookie test for the simultaneous determination of glucose intolerance, hyperinsulinemia, insulin resistance and postprandial dyslipidemia. Endocr J 2006, 53(2):173-180.

16. Corretti MC, Anderson TJ, Benjamin EJ, Celermajer D, Charbonneau F, Creager MA, Deanfield J, Drexler H, Gerhard-Herman M, Herrington D, Vallance P, Vita J, Vogel R: Guidelines for the ultrasound assessment of endothelial-dependent flow-mediated vasodilation of the brachial artery: a report of the International Brachial Artery Reactivity Task Force. J Am Coll Cardiol 2002, 39(2):257-265.

17. Kawano H, Motoyama T, Hirashima O, Hirai N, Miyao Y, Sakamoto T, Kugiyama K, Ogawa H, Yasue $H$ : Hyperglycemia rapidly suppresses flow-mediated endothelium-dependent vasodilation of brachial artery. J Am Coll Cardiol 1999, 34(1):146-154.

18. Qin X, Shen H, Liu M, Yang Q, Zheng S, Sabo M, D'Alessio DA, Tso P: GLP-1 reduces intestinal lymph flow, triglyceride absorption, and apolipoprotein production in rats. Am J Physiol Gastrointest Liver Physiol 2005, 288(5):G943-G949.

19. Wojdemann M, Wettergren A, Sternby B, Holst JJ, Larsen S, Rehfeld JF, Olsen $\mathrm{O}$ : Inhibition of human gastric lipase secretion by glucagon-like peptide1. Dig Dis Sci 1998, 43(4):799-805.

20. Hsieh J, Longuet C, Baker CL, Qin B, Federico LM, Drucker DJ, Adeli K: The glucagon-like peptide 1 receptor is essential for postprandial lipoprotein 
synthesis and secretion in hamsters and mice. Diabetologia 2010, 53(3):552-561.

21. Matsubara J, Sugiyama S, Sugamura K, Nakamura T, Fujiwara Y, Akiyama E, Kurokawa H, Nozaki T, Ohba K, Konishi M, Maeda H, Izumiya Y, Kaikita K, Sumida H, Jinnouchi H, Matsui K, Kim-Mitsuyama S, Takeya M, Ogawa H: A dipeptidyl peptidase-4 inhibitor, des-fluoro-sitagliptin, improves endothelial function and reduces atherosclerotic lesion formation in apolipoprotein E-deficient mice. JJ Am Coll Cardiol 2012, 59(3):265-276.

22. Shiraki A, Oyama J, Komoda H, Asaka M, Komatsu A, Sakuma M, Kodama K, Sakamoto Y, Kotooka N, Hirase T, Node K: The glucagon-like peptide 1 analog liraglutide reduces TNF-alpha-induced oxidative stress and inflammation in endothelial cells. Atherosclerosis 2012, 221(2):375-382.

23. van Poppel PC, Netea MG, Smits P, Tack CJ: Vildagliptin improves endothelium-dependent vasodilatation in type 2 diabetes. Diabetes Care 2011, 34(9):2072-2077.

24. Norata GD, Grigore L, Raselli S, Redaelli L, Hamsten A, Maggi F, Eriksson P, Catapano AL: Post-prandial endothelial dysfunction in hypertriglyceridemic subjects: molecular mechanisms and gene expression studies. Atherosclerosis 2007, 193(2):321-327.

25. Hiki M, Shimada K, Kiyanagi T, Fukao K, Hirose K, Ohsaka H, Fukushima Y, Kume A, Matsumori R, Sumiyoshi K, Miyazaki T, Ohmura H, Kurata T, Miida T, Daida H: Single administration of alpha-glucosidase inhibitors on endothelial function and incretin secretion in diabetic patients with coronary artery disease - Juntendo University trial: effects of miglitol on endothelial vascular reactivity in type 2 diabetic patients with coronary heart disease (J-MACH). Circ J 2010, 74(7):1471-1478.

26. Koska J, Schwartz EA, Mullin MP, Schwenke DC, Reaven PD: Improvement of postprandial endothelial function after a single dose of exenatide in individuals with impaired glucose tolerance and recent-onset type 2 diabetes. Diabetes Care 2010, 33(5):1028-1030.

27. Kazunari S, Kentaro W, Tatsuya S, Motoshi O, Shoko F-S, Yoshimasa I, Hiroshi $\mathrm{N}$, Kenzo O: Sitagliptin improves vascular endothelial function in Japanese type 2 diabetes patients without cardiovascular disease. Journal of Diabetes Mellitus 2012, 2(3):338-345.

28. Lim S, Choi SH, Shin H, Cho BJ, Park HS, Ahn BY, Kang SM, Yoon JW, Jang HC, Kim YB, Park KS: Effect of a dipeptidyl peptidase-IV inhibitor, desfluoro-sitagliptin, on neointimal formation after balloon injury in rats. PLoS One 2012, 7(4):e35007.

29. UK Prospective Diabetes Study (UKPDS) Group: Intensive blood-glucose control with sulphonylureas or insulin compared with conventional treatment and risk of complications in patients with type 2 diabetes (UKPDS 33). Lancet 1998, 352(9131):837-853.

30. Gerstein HC, Miller ME, Byington RP, Goff DC Jr, Bigger JT, Buse JB, Cushman WC, Genuth S, Ismail-Beigi F, Grimm RH Jr, Probstfield JL, Simons-Morton DG, Friedewald WT: Effects of intensive glucose lowering in type 2 diabetes. N Engl J Med 2008, 358(24):2545-2559.

31. Patel A, MacMahon S, Chalmers J, Neal B, Billot L, Woodward M, Marre M, Cooper M, Glasziou P, Grobbee D, Hamet P, Harrap S, Heller S, Liu L, Mancia G, Mogensen CE, Pan C, Poulter N, Rodgers A, Williams B, Bompoint S, de Galan BE, Joshi R, Travert F: Intensive blood glucose control and vascular outcomes in patients with type 2 diabetes. N Engl J Med 2008 358(24):2560-2572.

32. Duckworth W, Abraira C, Moritz T, Reda D, Emanuele N, Reaven PD, Zieve FJ, Marks J, Davis SN, Hayward R, Warren SR, Goldman S, McCarren M, Vitek ME, Henderson WG, Huang GD: Glucose control and vascular complications in veterans with type 2 diabetes. N Engl J Med 2009, 360(2):129-139.

33. Cobble ME, Frederich R: Saxagliptin for the treatment of type 2 diabetes mellitus: assessing cardiovascular data. Cardiovasc Diabetol 2012, 11:6.

34. Zhong J, Rao X, Rajagopalan S: An emerging role of dipeptidyl peptidase 4 (DPP4) beyond glucose control: Potential implications in cardiovascular disease. Atherosclerosis 2012, In press.

35. Yin M, Sillje HH, Meissner M, van Gilst WH, de Boer RA: Early and late effects of the DPP-4 inhibitor vildagliptin in a rat model of postmyocardial infarction heart failure. Cardiovasc Diabetol 2011, 10:85.

doi:10.1186/1475-2840-12-8

Cite this article as: Noda et al:: Alogliptin ameliorates postprandial lipemia and postprandial endothelial dysfunction in non- diabetic subjects: a preliminary report. Cardiovascular Diabetology 2013 12:8.

\section{Submit your next manuscript to BioMed Central and take full advantage of:}

- Convenient online submission

- Thorough peer review

- No space constraints or color figure charges

- Immediate publication on acceptance

- Inclusion in PubMed, CAS, Scopus and Google Scholar

- Research which is freely available for redistribution 